Portland State University

PDXScholar

$11-1-2005$

\title{
Contributions of Heterosis and Epistasis to Hybrid Fitness
}

Mitchell B. Cruzan

Portland State University

Follow this and additional works at: https://pdxscholar.library.pdx.edu/bio_fac

Part of the Biology Commons, and the Plant Breeding and Genetics Commons

Let us know how access to this document benefits you.

\section{Citation Details}

Rhode, J. M., and Cruzan, M. B. (2005). Contributions of Heterosis and Epistasis to Hybrid Fitness. American Naturalist, 166(5), E124-E139.

This Article is brought to you for free and open access. It has been accepted for inclusion in Biology Faculty Publications and Presentations by an authorized administrator of PDXScholar. Please contact us if we can make this document more accessible: pdxscholar@pdx.edu. 


\title{
Contributions of Heterosis and Epistasis to Hybrid Fitness
}

\author{
Jennifer M. Rhode ${ }^{*}$ and Mitchell B. Cruzan ${ }^{\dagger}$
}

Department of Biology, Portland State University, Portland, Oregon 97207

Submitted October 24, 2004; Accepted June 7, 2005;

Electronically published August 30, 2005

\begin{abstract}
AвSTRACT: Early-generation hybrid fitness is difficult to interpret because heterosis can obscure the effects of hybrid breakdown. We used controlled reciprocal crosses and common garden experiments to distinguish between effects of heterosis and nuclear and cytonuclear epistasis among morphotypes and advanced-generation hybrid derivative populations in the Piriqueta caroliniana (Turneraceae) plant complex. Seed germination, growth, and sexual reproduction of first-generation hybrids, inbred parental lines, and outbred parental lines were compared under field conditions. Average vegetative performance was greater for hybrids than for inbred lines, and firstseason growth was similar for hybrids and outbred parental lines. Hybrid survival surpassed that of inbred lines and was equal to or greater than outbred lines' survival, and more $\mathrm{F}_{1}$ than parental plants reproduced. Reductions in hybrid fitness due to Dobzhansky-Muller incompatibilities (epistasis among divergent genetic elements) were expressed as differences in vegetative growth, survival, and reproduction between plants from reciprocal crosses for both $\mathrm{F}_{1}$ and backcross hybrid generations. Comparing performance of hybrids against parental genotypes from intra- and interpopulation crosses allowed a more robust prediction of $F_{1}$ hybrids' success and more accurate interpretations of the genetic architecture of $F_{1}$ hybrid vigor.
\end{abstract}

Keywords: Cytonuclear epistasis, field transplants, heterosis, inbreeding depression, hybrid breakdown, introgression.

The exchange of genetic material among divergent lineages has been a potent evolutionary force in a variety of plant and animal groups (Stebbins 1959; Knobloch 1972; Harrison 1990; Arnold 1997; Dowling and Secor 1997) and may be a mechanism for the acquisition of adaptive genetic elements (Anderson 1949; Anderson and Stebbins 1954;

\footnotetext{
* Present address: Department of Biological and Environmental Sciences, Georgia College and State University, CBX 081, Milledgeville, Georgia 31061; e-mail: jennifer.rhode@gcsu.edu.

† E-mail: cruzan@pdx.edu.
}

Am. Nat. 2005. Vol. 166, pp. E124-E139. (C) 2005 by The University of Chicago. 0003-0147/2005/16605-40699\$15.00. All rights reserved.
Stebbins 1959; Grant 1963; Rieseberg et al. 1999). However, genomic integration among taxa via hybridization is a complex process because offspring from crosses between divergent lineages often express diminished viability and fertility (Muller 1942; Templeton 1981; Orr 1996; Arnold 1997; Dowling and Secor 1997). Reductions in hybrid fitness (hereafter "hybrid breakdown") may be a consequence of chromosomal rearrangements (Grant 1981; Fishman and Willis 2001), maladaptive trait combinations (Schluter 1998; Hatfield and Schluter 1999; Schemske 2000; Via 2002), or epistasis among divergent genomic elements (Dobzhansky-Muller incompatibilities; Dobzhansky 1936; Muller 1942; Orr 1995; Turelli and Orr 2000; Orr and Turelli 2001). Alternatively, the fitness of early-generation hybrids may be increased because of heterosis (i.e., because of dominance and overdominance at loci fixed for inferior alleles in the parental populations) after crosses among inbred populations (Lynch 1991; Hedgecock et al. 1995; Burke and Arnold 2001). While heterosis has the potential to counteract fitness losses due to epistasis in early-generation hybrids, the effects of outcrossing are not typically considered in studies of earlygeneration hybrid fitness.

Our understanding of hybrid breakdown as a mechanism for reproductive isolation is based primarily on the model proposed by Dobzhansky $(1936,1937)$ and Muller $(1940,1942)$ and then further developed by Orr and colleagues (Orr 1995; Coyne and Orr 1998; Turelli and Orr 2000; Orr and Turelli 2001). In the Dobzhansky-Muller model, hybrid inferiority results from interactions among new mutations that have become fixed in diverging lineages (Dobzhansky 1936; Muller 1942; Orr 1995), so reproductive isolation can evolve without fitness loss. According to this model, if the ancestral genotype were $a a b b$, divergent lineages might become fixed for mutations at different loci $\left(a^{\prime} a^{\prime} b b\right.$ and $\left.a a b^{\prime} b^{\prime}\right)$. First-generation hybrids $\left(a a^{\prime} b b^{\prime}\right)$ would be expected to have reduced viability due to epistatic interactions between the $a^{\prime}$ and $b^{\prime}$ alleles (Orr 1995; Coyne and Orr 1998). Similarly, reductions in hybrid viability could be a consequence of epistasis between divergent nuclear and cytoplasmic genetic elements (i.e., $a a^{\prime}-c^{\prime}$ or $\left.b b^{\prime}-c^{\prime}\right)$. Because mutations contributing to hybrid breakdown are operationally neutral in their native genetic 
backgrounds and because each allele has the potential for multiple interactions, the accumulation of DobzhanskyMuller incompatibilities is expected to be exponential (Orr 1995).

Many theoretical and empirical studies have focused on loss of fitness in hybrids, but if populations of the parental taxa are inbred, early-generation hybrids may instead display heterosis and increased fitness. Limited dispersal and small population size can lead to local inbreeding (Wright 1932; Fisher 1965; Hedrick and Miller 1992), which often results in fixation of mildly deleterious mutations (Hartl and Clark 1997). Because inbreeding depression is likely to be the consequence of many alleles of small effect (Charlesworth and Charlesworth 1987), we would expect populations of divergent taxa to become fixed for different sets of deleterious recessive alleles. Crossing between taxa would produce hybrids with higher fitness because a larger proportion of the loci segregating for deleterious alleles would be heterozygous. Examples of increases in the vigor of offspring in the generation following an intraspecific interpopulation cross are common (Darwin 1876; Dobzhansky 1937; Stebbins 1950; Mayr 1963; Charlesworth and Charlesworth 1987; Galloway and Fenster 1999; Fenster and Galloway 2000). Similarly, interbreeding among closely related taxa is likely to result in heterosis for hybrid offspring (Lynch 1991). However, the positive effects of isolated incidences of outcrossing will be transient, as the level of heterozygosity in offspring will decrease with each hybrid generation after the first (Burke and Arnold 2001). The expected boost in vigor of early-generation hybrids due to increased heterozygosity could be critical for the establishment of hybrid populations and the initiation of introgression (Arnold 1997), but analyses isolating the specific contributions of heterosis to early-generation hybrid vigor have not been conducted. The high frequency of biparental inbreeding as a consequence of small effective population size in many plant species (Charlesworth and Charlesworth 1987) renders them an ideal experimental system for analyses of the contributions of heterosis and epistasis to early-generation hybrid vigor.

Here we compare hybrid, inbred, and outbred parental crosses to assess the relative contributions of heterosis and epistasis to first-generation hybrid fitness in an herbaceous perennial plant. We expect that the contribution of heterosis to $F_{1}$ hybrid fitness may lead to overestimates of hybrid vigor and obfuscate the severity of hybrid breakdown. However, the majority of recent studies of firstgeneration hybrid fitness use parental genotypes that are probably inbred (table 1). Because the effects of heterosis diminish in later hybrid generations (i.e., because of the reduction in the frequency of heterozygous loci as a consequence of segregation), interpretation of studies that use
Table 1: Survey of primary literature published from 1993 to 2003 that compared fitness of animal or plant $F_{1}$ hybrids to parentals under field or laboratory conditions

\begin{tabular}{lccc}
\hline & \multicolumn{3}{c}{ Parental genotypes } \\
\cline { 2 - 4 } Result & Inbred, field & Inbred, lab & Outbred \\
\hline Equal or superior & 6 & 7 & 0 \\
Intermediate & 3 & 2 & 1 \\
Inferior & 1 & 1 & 0 \\
Depends on environment & 0 & 3 & 0 \\
\hline
\end{tabular}

inbred parental genotypes (i.e., those derived from withinpopulation crosses) for comparison may be misleading with respect to the expected persistence of hybrid genotypes and hybrid populations.

The parental group to which $\mathrm{F}_{1}$ hybrid fitness should be compared depends on the study's goals. For example, when analyzing the genetic architecture of hybrid breakdown, it is best to use outbred (between-population crosses) parental lines for comparison. Contrasting hybrid and inbred (within-population crosses) parental genotypes can underestimate the severity of hybrid breakdown because parentals, with their fixed deleterious recessive alleles, may seem relatively unfit (e.g., Emms and Arnold 1997; Dunham and Argue 2000; Parris et al. 2001; Hauser et al. 2003). To predict the performance of newly formed hybrid genotypes within parental populations, on the other hand, it may be more appropriate to compare hybrids with inbred (within-population) parental crosses, the genotypes with which they would compete under field conditions. Knowing the degree to which populations are inbred will allow a more accurate assessment of their invasibility by migrant genomes (e.g., Richards 2000; Ebert et al. 2002; Haag et al. 2002; Marr et al. 2002). Furthermore, comparing hybrid genotypes from reciprocal crosses to both inbred and outbred parental genotypes generates a more accurate assessment of the ways in which hybrid fitness is affected by heterosis, intergenomic incompatibilities (i.e., negative intergenomic epistasis among alleles; Dobzhansky 1936; Muller 1942; Orr 1995; Coyne and Orr 1998; Fenster and Galloway 2000), and cytonuclear interactions (Burke et al. 1998a, 1998b; Galloway and Fenster 1999; Campbell and Waser 2001; Willett and Burton 2001).

In this study, we use reciprocal crosses to compare fitness of first-generation hybrid genotypes with both inbred and outbred parental lines and to assess the consequences of cytoplasmic genetic background for hybrid fitness under field conditions. First-generation hybrid genotypes and within-population parental (inbred) crosses were compared to provide a baseline for estimating the levels of heterosis and to forecast the success of hybrid genotypes 
in the field. The $\mathrm{F}_{1}$ hybrid and among-population (outbred) crosses were compared to determine the effects of intergenomic epistasis (i.e., Dobzhansky-Muller incompatibilities; Dobzhansky 1936; Muller 1942). We expected that if intergenomic nuclear or cytonuclear incompatibilities were absent or negligible, then the fitness of $\mathrm{F}_{1}$ hybrids would be at least as high as that of outbred progeny. The results from these comparisons provide a clearer picture of the contributions of epistasis and heterosis to hybrid fitness and allow predictions of the consequences of $\mathrm{F}_{1}$ hybrid formation for both the evolutionary trajectory of populations and hybrid zone dynamics.

\section{Hybridization in the Piriqueta caroliniana Complex}

The Piriqueta caroliniana (Turneraceae) complex is a group of closely related herbaceous perennials with a North American distribution from southern Florida to southern Georgia. Plants in this complex are distylous and have stringent self- and intrastyle morph incompatibility, as demonstrated by attempts (ours and those of others) to cross these plants under greenhouse conditions (Ornduff and Perry 1964; Wang and Cruzan 1998). We focused on two morphotypes and their natural hybrids-viridis (V) in the south, caroliniana (C) in the north, and their advanced-generation hybrid derivatives (hereafter, $\mathrm{H}$ or hybrid derivative)-from the broad hybrid zone across central Florida. Hybrid derivatives $(\mathrm{H})$ were represented by populations toward the center of the natural hybrid zone that were morphologically uniform and did not display evidence of recent introgression (i.e., disequilibria among markers diagnostic for the parentals were near 0 ; Handy et al. 2004). H genotypes were treated as a third parental type in this study because populations are relatively old, have persisted for many generations after initial hybridization (Maskas and Cruzan 2000; Handy et al. 2004), and appear to be genetically stable (i.e., they produce consistent phenotypes after several generations of crosses; M. B. Cruzan, unpublished data). This species is an obligate outcrosser (i.e., not self-compatible), but populations of Piriqueta are relatively small (generally $<100$; M. B. Cruzan, unpublished data) and, based on an allozyme survey of polymorphic loci in the $\mathrm{C}$ morphotype, are typically inbred $(f=0.67$; Weir and Cockerham 1984; Hartl and Clark 1997; 95\% confidence interval $=0.42$ 0.92 from 1,000 bootstraps across six loci in seven populations).

The natural hybrid zone that is the focus of this study covers approximately $300 \mathrm{~km}$ of central Florida from Lake Okeechobee in the south to Lake City in the north. Genetic and biogeographic data indicate that hybridization was probably initiated in south Florida $<5,000-7,000$ years ago, and the hybrid zone has expanded northward since then
(Maskas and Cruzan 2000). Clinal data for genetic markers and morphological variation are consistent with hybrid zone expansion by the introgression of $\mathrm{V}$ genes northward, and sharp clines in some markers suggest that selection against early-generation hybrids restricts gene flow toward the south (Martin and Cruzan 1999). The presence of such a large environmentally heterogeneous region occupied solely by hybrids may indicate that hybrids outcompete parental genotypes in a wide range of habitats. Alternatively, this pattern might be due to demographic swamping, with high rates of introgression from the south, which would be facilitated by heterosis of $\mathrm{F}_{1}$ hybrids.

In our assessment of the consequences of hybridization in this system, we mimicked scenarios likely to occur during the establishment and expansion of this broad natural hybrid zone. In Piriqueta, populations are relatively isolated (separated by $>2 \mathrm{~km}$; M. B. Cruzan, personal observation). Because seeds are apparently not adapted for long-distance dispersal (i.e., they drop from dry capsules and may be carried by ants over short distances; M. B. Cruzan, personal observation), $F_{1}$ hybrids would be formed via long-distance pollen dispersal. Hence, we expect that the formation of $F_{1}$ hybrids would be episodic and relatively infrequent. Each of the scenarios we assess represents one of six possible pathways for introgression into and out of the region of hybridization $(\mathrm{C} \times \mathrm{H}$, $\mathrm{V} \times \mathrm{H})$ and between the original parental taxa $(\mathrm{C} \times \mathrm{V})$. Reciprocal crosses (e.g., CV vs. VC, where the first letter indicates the maternal morphotype) were used to assess consequences of $F_{1}$ hybrid formation in each parental population and to test for disparities in hybrid performance due to differing cytoplasmic backgrounds (e.g., Burke et al. 1998b; Galloway and Fenster 1999; Campbell and Waser 2001; Willett and Burton 2001). Pairs of reciprocal crosses from a backcross $\left(\mathrm{F}_{1}\right.$ hybrid $\times$ parental $)$ hybrid generation were also assessed. All comparisons were made in common gardens in a field site representative of typical Piriqueta habitat.

Here we explore the factors that maintain this broad Piriqueta hybrid zone. Specifically, we ask whether firstgeneration hybrids would persist because they were more fit than inbred individuals, the ones that would be most abundant in natural sites, and whether $F_{1}$ hybrid breakdown was masked by heterotic effects (Lynch 1991). We also asked whether sharp clines at the southern extent of hybridization might have been formed in response to selection against $\mathrm{F}_{1}$ hybrids, as suggested by Barton and Gale (1993). To address these questions, we produced inbred parental, outbred parental, $F_{1}$ hybrid, and first-generation backcross hybrid $\left(\mathrm{F}_{1}\right.$ hybrid $\times$ parental $)$ plants through a series of artificial matings, transplanted them to field sites, and monitored their survival, growth, and reproduction during two seasons. The results provide evidence 
that variation in vegetative and reproductive fitness among parental and hybrid genotypes may be an important influence on the dynamics of this expanding hybrid zone.

\section{Material and Methods}

\section{Crosses and Propagation}

In summer 2000, we collected seeds from allopatric Piriqueta populations of $\mathrm{C}$ (189 fruits from 14 populations) and V (261 fruits from 10 populations) morphotypes and from $\mathrm{H}$ populations (166 fruits from 11 populations) in the center of the natural hybrid zone. Previous analyses indicate that populations at the center of the hybrid zone are relatively old (many dozens of generations) and have not been subject to recent introgression from allopatric regions (Martin and Cruzan 1999; Maskas and Cruzan 2000; Handy et al. 2004). Physical distances between pairs of populations ranged from 9 to $160 \mathrm{~km}(\mathrm{C})$, from 6 to $35 \mathrm{~km}(\mathrm{H})$, and from 8 to $77 \mathrm{~km}(\mathrm{~V})$.

We designed our crossing experiments to minimize nongenetic maternal effects. In summer 2000, field-collected seeds were germinated under greenhouse conditions. Then, in fall 2000, these greenhouse-germinated plants were crossed to yield seeds used in field experiments. Crosses were made randomly to include as many population pairs as possible. Three types of offspring were produced, using the same parent plants in different combinations: outbred (subscript "o") genotypes, which were the products of matings between individuals from different populations of the same parental type $(\mathrm{C}, \mathrm{H}$, or $\mathrm{V})$; inbred (subscript "i") genotypes, which were produced by matings between plants from different maternal families within the same population $(\mathrm{C}, \mathrm{H}$, or $\mathrm{V})$; and $\mathrm{F}_{1}$ hybrid genotypes $(\mathrm{C} \times \mathrm{V}, \mathrm{C} \times \mathrm{H}$, and $\mathrm{H} \times \mathrm{V}$, plus the reciprocals of each cross). Seeds used in field experiments were taken randomly from the following numbers of reciprocally crossed combinations (sibships): $\mathrm{C}_{\mathrm{i}}(8), \mathrm{C}_{\mathrm{o}}(15), \mathrm{H}_{\mathrm{i}}(4), \mathrm{H}_{\mathrm{o}}(14)$, $\mathrm{V}_{\mathrm{i}}(5), \mathrm{V}_{\mathrm{o}}(13), \mathrm{CH}$ (9; first letter indicates the maternal parent), CV (7), HC (10), HV (8), VC (9), and VH (6). Seeds from each sibship were divided equally into two lots; one lot was planted directly into common gardens, while the other was established in a greenhouse before being transplanted into the field site.

In fall and winter 2001, $F_{1}$ hybrid genotypes were reciprocally backcrossed to both of their parental types to test for effects of cytonuclear epistasis in a later hybrid generation. We produced pairs of reciprocal backcross genotypes that would allow us to contrast effects of different cytoplasmic genotypes (maternal parent) in a single nuclear background. Crosses for six reciprocal backcross hybrid pairs were produced: $(\mathrm{CV}) \mathrm{C}$ versus $(\mathrm{VC}) \mathrm{C}$,
$(\mathrm{CV}) \mathrm{V}$ versus $(\mathrm{VC}) \mathrm{V},(\mathrm{CH}) \mathrm{C}$ versus $(\mathrm{HC}) \mathrm{C},(\mathrm{CH}) \mathrm{H}$ versus $(\mathrm{HC}) \mathrm{H},(\mathrm{VH}) \mathrm{H}$ versus $(\mathrm{HV}) \mathrm{H}$, and $(\mathrm{VH}) \mathrm{V}$ versus $(\mathrm{HV}) \mathrm{V}$. Seeds from 10 to 65 fruits per backcross type were germinated in the greenhouse, and cuttings were made of adult plants. Cuttings were allowed to establish under greenhouse conditions for 4 weeks before transplanting.

\section{Field Common Garden Experiments: Planting Design}

Common field gardens were established on the grounds of Archbold Biological Station (Venus, FL), near the southern edge of the naturally occurring Piriqueta hybrid zone. Garden transplant sites were located in yellow sandhill, turkey oak scrub sites (Red Hill) in areas that matched typical natural habitat for northern and central populations of this species (edges, relatively open with sparse vegetation). Garden sites were separated from naturally occurring Piriqueta populations by several kilometers. Plants in these sites were exposed to naturally occurring levels of nutrients, light, and moisture, without supplementation, and were planted within natural plant and animal communities. In central Florida, Piriqueta flowering typically commences in late April, but drought conditions prevent seeds from germinating until the summer rains begin in mid-June. We timed our field planting to mimic the natural phenology of Piriqueta and to increase the probability of plant survival through the first season.

Seed and seedling plots (four $1-\mathrm{m}^{2}$ plots each) were arranged at 1-2-m intervals along the edges of unpaved fire roads. Seeds and seedlings were randomly assigned to $10-\mathrm{cm}^{2}$ cells within each of the four plots such that all cross types were distributed evenly within and among plots. In May 2001, half of the seeds from each fruit were divided into lots of one to three seeds, and each lot was planted into a $2.5-\mathrm{cm}$-diameter by $3.0-\mathrm{cm}$-tall peat pellet (one to five pellets per fruit). Seeds in peat pellets were allowed to germinate and establish for 3 weeks in the greenhouse and were acclimated to outside conditions for 1 week before being transplanted (with their associated peat pellets) to field gardens in July 2001. By the time plants were moved to the field, most emerging seedlings had begun to develop adult leaves. In mid-June, the second lot of seeds was planted directly into four $1-\mathrm{m}^{2}$ field plots. Seeds from each fruit were divided into lots of one to three seeds, and each lot was placed approximately $1 \mathrm{~cm}$ beneath the quartz sand soil's surface in the center of a $10-\mathrm{cm}^{2}$ cell (one to five cells per fruit). In July 2002, nine to 30 backcross hybrids of each type were randomly selected from greenhouse cuttings. These plants, along with their associated peat pellets, were planted in field gardens at Archbold Biological Station 
in an incomplete block design using the same spatial arrangement described above.

\section{Field Common Garden Experiments: Measurements and Monitoring}

Beginning in July 2001, both sets of seedlings were monitored every week for the first 6 weeks and every 2 weeks for the last 4 weeks (a total of 12 weeks) during the JulySeptember growing season. Each week, we recorded the number of seedlings, seedling mortality, and the height, number of leaves, and number of reproductive structures (buds, flowers, and fruits) for each living seedling. Extra seedlings were culled randomly at the end of the first season, and one plant per cell was monitored for a second season in late May, mid-August, and late September 2002.

Between July and October 2002, backcross gardens were monitored every 6 weeks (for a total of four monitoring times). Each week, we recorded the heights, numbers of leaves, and numbers of reproductive structures (buds, flowers, and fruits) for all living cuttings.

\section{Data Analyses}

Data were analyzed to assess separately the effects of cross group (inbred parental, outbred parental, or $\mathrm{F}_{1}$ ) and cross type (each inbred or outbred parental and all reciprocal $\mathrm{F}_{1}$ crosses) on seed germination, vegetative growth, reproduction, and survival during two growing seasons. Our analyses compared each $\mathrm{F}_{1}$ cross with inbred and outbred parental genotypes; we also compared $\mathrm{F}_{1}$ crosses with midparent averages. Thus, we were able to assess the contributions of both heterosis and epistasis to hybrid fitness.

Seed germination in native sand soils and in peat blocks was analyzed using categorical models with the CATMOD procedure of SAS (SAS Institute 1999). The effects of cross group and cross type on the germination of seeds from each fruit were analyzed in two separate models that included plot as a blocking factor to control for spatial variation in the garden. Germination and early seedling survival were relatively poor in the native soil garden, resulting in small sample sizes, so data from these plants were not analyzed further.

Vegetative size of peat seedlings and backcross cuttings was calculated as the product of plant height and leaf number. This estimate of aboveground biomass appeared to be independent of potentially confounding phylogenetically derived morphological traits (i.e., under greenhouse conditions, parental genotypes did not differ for this value; M. B. Cruzan, unpublished data), and it provided an approximation of fitness differences associated with plant size. This measure was square root transformed to correct for heterogeneity of variance before all analyses.
Repeated-measures ANOVA with the GLM procedure of SAS (SAS Institute 1999) was used to assess separately the effects of cross group and cross type on vegetative size of peat-planted seedlings during each of the two field seasons. Separate analyses were also conducted for the first (five censuses) and the second (three censuses) growing seasons for the seedlings and the first season (four censuses) for the backcross cuttings. In these analyses, plants were grouped by plot position, which was entered into models as a random blocking factor to remove spatial effects. Cross type was treated as a fixed effect, time was the number of days since planting, and size at the end of the first season was used as a covariate in the analysis of second-season growth. First- and second-season growth were analyzed separately because of the large number of plants that did not survive the first winter.

Vegetative size at the end of each growing season was analyzed to test a priori hypotheses for differences among inbred and outbred parentals and $F_{1}$ hybrids and between pairs of reciprocal backcrosses using contrast statements in ANOVA models. Plot position was entered as a blocking factor for both seasons, and size at the end of the first season was entered as a covariate as described above. Separate contrast tests were done between each pair of inbred and outbred parental crosses, each hybrid cross and its inbred parentals (pooled as a midparent value), and each hybrid and its outbred parentals (pooled as a midparent value). Separate contrast tests were conducted to analyze paired crosses, which allowed us to test for effects of different cytotypes in nuclear background of similar composition: $(\mathrm{CV}) \mathrm{C}$ versus $(\mathrm{VC}) \mathrm{C},(\mathrm{CV}) \mathrm{V}$ versus $(\mathrm{VC}) \mathrm{V}$, $(\mathrm{CH}) \mathrm{C}$ versus $(\mathrm{HC}) \mathrm{C},(\mathrm{CH}) \mathrm{H}$ versus $(\mathrm{HC}) \mathrm{H},(\mathrm{VH}) \mathrm{H}$ versus $(\mathrm{HV}) \mathrm{H}$, and $(\mathrm{VH}) \mathrm{V}$ versus $(\mathrm{HV}) \mathrm{V}$. Contrasts did not exceed the number of degrees of freedom available for each effect, so Type I error corrections were not necessary (Zar 1999).

We analyzed the reproductive output for individual plants during both growing seasons using two separate approaches. First, we assessed the factors affecting whether plants ever reproduced using categorical models with the CATMOD procedure of SAS (SAS Institute 1999). Second, we examined plants' total reproductive output, calculated as the sum of all buds, flowers, and fruits produced during both seasons. Differences in reproductive output by cross group and type were assessed using ANOVA with the GLM procedure of SAS (SAS Institute 1999). In these analyses, the dependent variable was total reproductive output; independent variables were cross group or type, with blocking factors and covariates as described above. Tests among inbred, outbred, and $\mathrm{F}_{1}$ crosses were conducted using contrast statements as described above.

Survival at the end of the first and second growing seasons was analyzed using categorical models with the 
CATMOD procedure of SAS (SAS Institute 1999). These models included plot location as a blocking factor. Vegetative size at the end of the first season was used as a covariate in logistic regression when analyzing survival to the end of the second season.

\section{Results}

\section{Parental and $F_{1}$ Hybrid Genotypes}

Cross groups (outbred parentals, inbred parentals, or $\mathrm{F}_{1}$ hybrid) and individual cross types differed significantly for measures of germination, plant growth, survival, and reproduction. Overall germination rates of seeds planted in sand were relatively low $(39.5 \%)$ and did not vary by cross group $\left(\chi^{2}=0.63, P=.73, \mathrm{df}=2,284\right)$ or by cross type $\left(\chi^{2}=7.05, P=.80, \mathrm{df}=11,284\right)$. The number of plants present in the sand-seedling garden was relatively small, so these were excluded from remaining analyses of plant growth, survival, and reproduction. Germination rates were higher for seeds planted into peat blocks (49.6\%), and there were nearly significant differences among cross groups $\left(\chi^{2}=5.94, P=.0513, \mathrm{df}=2,284\right)$, with outbred seeds germinating best and inbred seeds germinating worst (fig. 1a). Among cross types, HV seeds germinated best (fig. $2 a ; \chi^{2}=41.26, P=.0001, \mathrm{df}=11,284$ ).

There were differences among cross groups for vegetative size during the first (fig. $3 a$; repeated-measures analysis: $F=3.42, P=.0338, \mathrm{df}=2,411$ ) but not the second (fig. $3 b$; repeated-measures analysis: $F=2.37, P=.10$, $\mathrm{df}=2,67)$ growing seasons. In the first year, outbred plants attained the largest size, followed by hybrids, and inbred plants tended to be the smallest. In the second year, hybrids were largest, though they were not significantly larger than outbred parentals, and both groups were larger than inbred plants. There were overall effects of cross type on vegetative size during the first growing season (repeated-measures analysis: $F=3.17, P=.0004, \mathrm{df}=$ $11,402)$. Though trends in the second-year data tracked those from the first, overall differences among types were not significant (repeated-measures analysis: $F=1.85$, $P=.07, \mathrm{df}=11,58)$. There was a significant plot effect for vegetative biomass for the first year (analysis by type: $F=3.17, \quad P=.0042$, $\mathrm{df}=3,402$; analysis by group: $F=4.28, P=.0055, \mathrm{df}=3,411)$ but not the second year (analysis by type: $F=0.89, P=.42, \mathrm{df}=2,58$; analysis by group: $F=0.77, P=.47, \mathrm{df}=2,67)$. Vegetative size attained at the end of the first year was strongly correlated with overall growth in the second season (analysis by type: $F=12.57, P=.0008, \mathrm{df}=1,58$; analysis by group: $F=13.83, P=.0004, \mathrm{df}=1,67)$. When vegetative size attained at the end of the first year was removed as a covariate, second-year differences among cross types and groups became more pronounced (analysis by type: $F=$ $2.32, P=.0100, \mathrm{df}=11,284$; analysis by group: $F=$ $8.09, P=.0010, \mathrm{df}=2,284)$.

The vegetative size attained at the end of the first season differed significantly among cross types $(F=3.81, P=$ $.0001, \mathrm{df}=11,418)$. Significant differences in plant size were detected for comparisons between inbred and outbred C parental genotypes (table 2). In the first season, there were significant differences in vegetative size between VH hybrids and both their outbred $(P=.0009)$ and inbred $(P=.0200)$ parental midparent averages (fig. $2 b)$. There were differences in biomass between $\mathrm{HV}$ and $\mathrm{VH}$ reciprocal hybrids; HV plants were larger (table 3; $P=$ .0020). Other reciprocal $F_{1}$ hybrids did not differ from one another.

Biomass accumulation also differed significantly among cross types at the end of the second growing season $(F=1.98, P=.0323, \mathrm{df}=11,183)$; plant sizes differed significantly between inbred and outbred $\mathrm{H}$ parentals (table 2; $P=.0164)$. Again, HV hybrids attained more biomass than their $\mathrm{VH}$ reciprocal counterparts (table 3; $P=.0312)$. At the end of the second growing season, $\mathrm{CV}$ hybrids were larger than their reciprocal crosses $(\mathrm{VC})$; this difference was nearly significant (table 3; $P=.0532$ ). There were significant differences between several of the $F_{1}$ hybrids and their midparent averages in the second season, including between $\mathrm{HC}$ and both inbred $(P=$ $.0563)$ and outbred $(P=.0149)$ parentals (fig. $2 c)$.

Whether a plant ever reproduced (during the 2 years of monitoring) varied significantly by group (fig. $1 b$; $\left.\chi^{2}=14.30, P=.0008, \mathrm{df}=2\right)$; more $\mathrm{F}_{1}$ hybrids reproduced than either outbred or inbred parental genotypes. Total reproductive output of peat-planted seedlings over the two growing seasons varied by group $(F=4.87$, $P=.0080, \mathrm{df}=2,89)$, with $\mathrm{F}_{1}$ hybrids $(P=.0026)$ and outbred plants $(P=.0322)$ reproducing more than inbred parentals. Whether a plant reproduced varied significantly by cross type (fig. $4 a ; \chi^{2}=27.92, P=.0033, \mathrm{df}=11$ ), and total reproduction varied as a consequence of cross type $(F=2.09, P=.0193, \mathrm{df}=11,80)$. Significant differences in reproductive output were detected between HC and both inbred $(P=.0004)$ and outbred $(P=.0008)$ parentals and also between $\mathrm{CV}$ and both inbred $(P=$ $.0081)$ and outbred $(P=.0366)$ parentals. No reciprocal hybrids differed from one another in their reproductive output (table 3).

Seedling survival to the end of the first growing season did not vary by group $\left(\chi^{2}=0.39, P=.82, \mathrm{df}=2\right)$ but did vary significantly among plots $\left(\chi^{2}=69.96, P=\right.$ $.0001, \mathrm{df}=3)$. Survival to the end of the second growing season varied significantly among groups $\left(\chi^{2}=7.06\right.$, $P=.0294, \mathrm{df}=2)$, with mortality highest for inbred plants and lowest for $\mathrm{F}_{1}$ hybrids (fig. 1c). There were also 

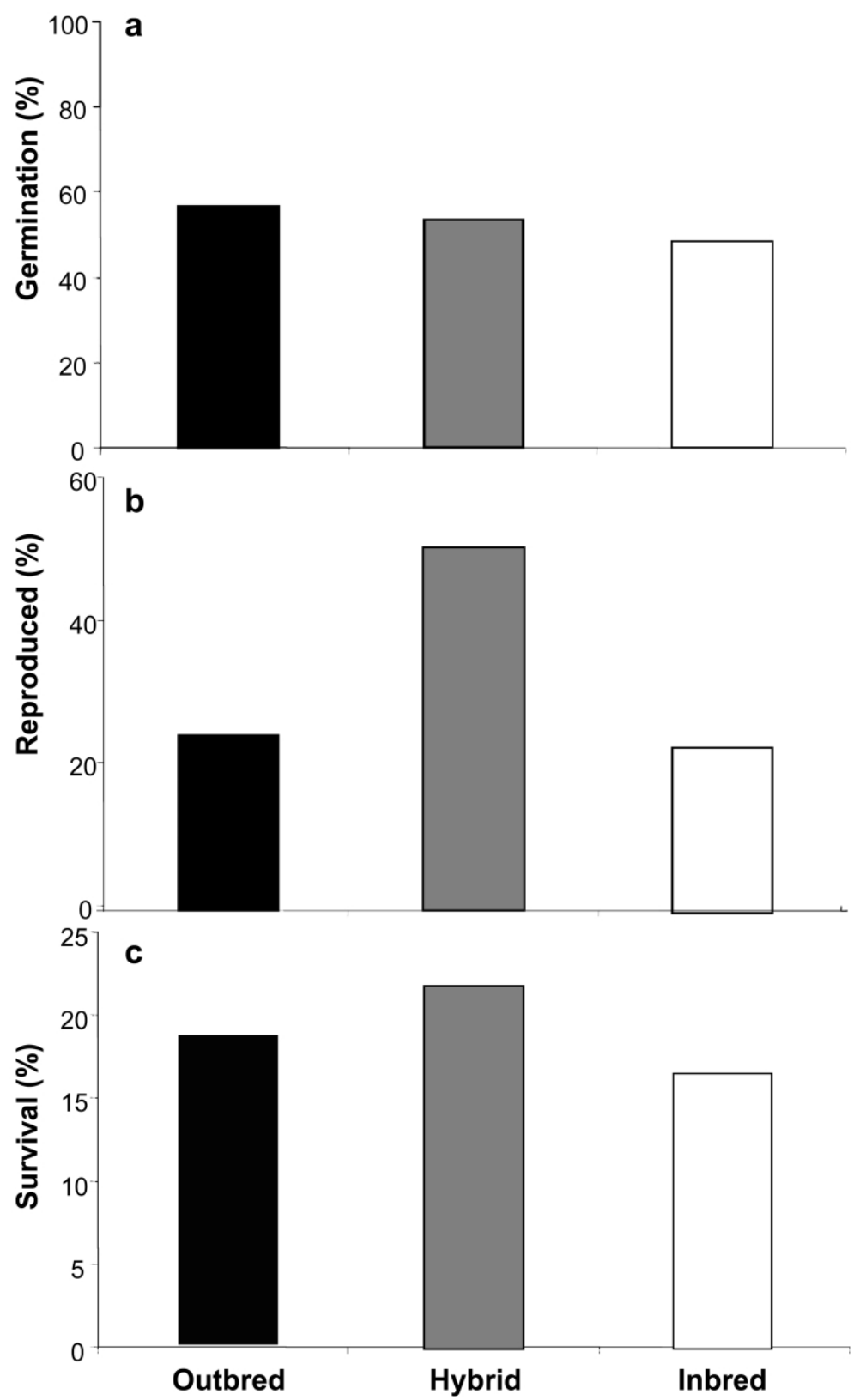

Figure 1: Means of outbred, inbred, and hybrid genotypes of Piriqueta caroliniana for $(a)$ percent germination of peat-planted seeds, $(b)$ percent of individual peat plants that reproduced during two growing seasons, and $(c)$ percent of plants that survived to the end of the second growing season. Because data indicate frequencies, no standard errors are included. In this and subsequent figures, black bars indicate outbred parental genotypes, white bars indicate inbred parental genotypes, and gray bars indicate hybrid genotypes.

significant effects of plot $\left(\chi^{2}=41.93, P=.0001, \mathrm{df}=\right.$ $3)$ and of size at the end of the first season $\left(\chi^{2}=57.25\right.$, $P=.0001, \mathrm{df}=1)$, with the largest plants having the highest overwinter survival. Survival of seedlings to the end of the first or second growing seasons did not differ significantly by cross type (first year: $\chi^{2}=15.53, P=$
$.16, \mathrm{df}=1$; second year: $\chi^{2}=15.00, P=.18, \mathrm{df}=11$; fig. $4 b$ ).

\section{Backcross Genotypes}

Vegetative size attained by the end of the first growing season differed significantly for two sets of reciprocal 


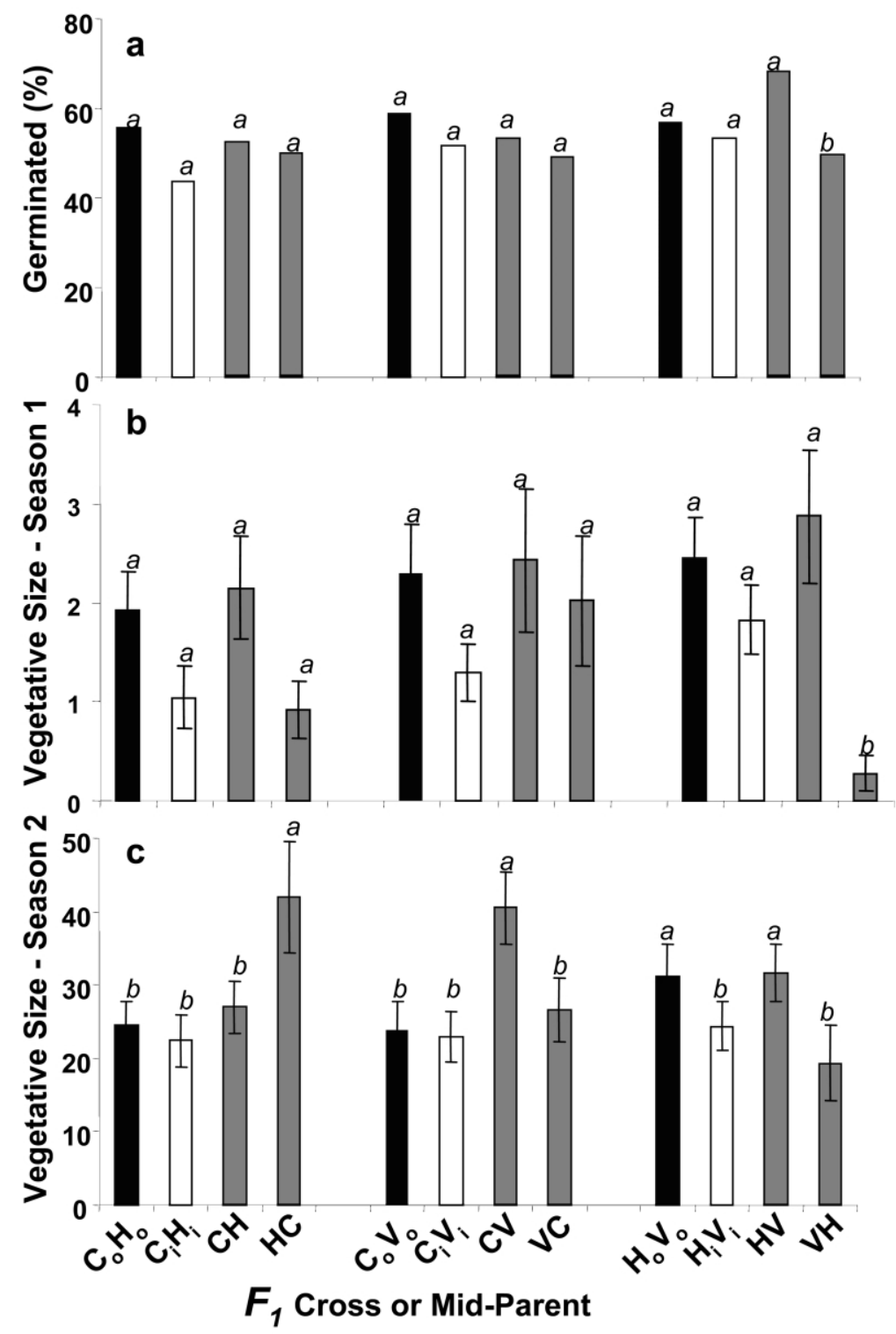

Figure 2: Means ( \pm 1 SE for nonfrequency data) of outbred, inbred, and hybrid genotypes of Piriqueta caroliniana for $(a)$ percent germination of peat-planted seeds, $(b)$ vegetative size at end of the first growing season, and $(c)$ vegetative size at the end of the second growing season. Vegetative size was estimated as the product of plant height and leaf number. $\mathrm{F}_{1}$ hybrid reciprocal crosses are grouped with the midparent values of both inbred (subscript "i"; e.g., $\mathrm{C}_{\mathrm{i}} \mathrm{H}_{\mathrm{i}}=$ midparent value of inbred $\mathrm{C}$ and $\mathrm{H}$ lines) and outbred (subscript "o") parental lines. Within each family group (outbred midparent, inbred midparent, and reciprocal hybrids), means sharing a letter do not differ significantly.

crosses (fig. 5); (HC)H plants were significantly larger than $(\mathrm{CH}) \mathrm{H}$ genotypes $(F=4.76, P=.0304, \mathrm{df}=11,190)$, and $(\mathrm{CV}) \mathrm{V}$ genotypes were significantly larger than $(\mathrm{VC}) \mathrm{V}$ genotypes $(F=5.44, P=.0208, \mathrm{df}=11,190)$. Sizes of other reciprocal pairs did not vary significantly.

\section{Discussion}

The relative growth and reproductive success of firstgeneration hybrids depend on whether they are compared with parental genotypes from within- or among-population crosses. Clear vegetative size differences among individual Piriqueta hybrid and parental crosses reflected the cumulative effects of heterosis and epistasis among nuclear and cytoplasmic genomes. After one season of growth under field conditions, $\mathrm{F}_{1}$ hybrids displayed greater aboveground biomass and higher rates of survival and reproduction than inbred parental lines, and their biomass was similar to that of outbred parental genotypes. The observed 

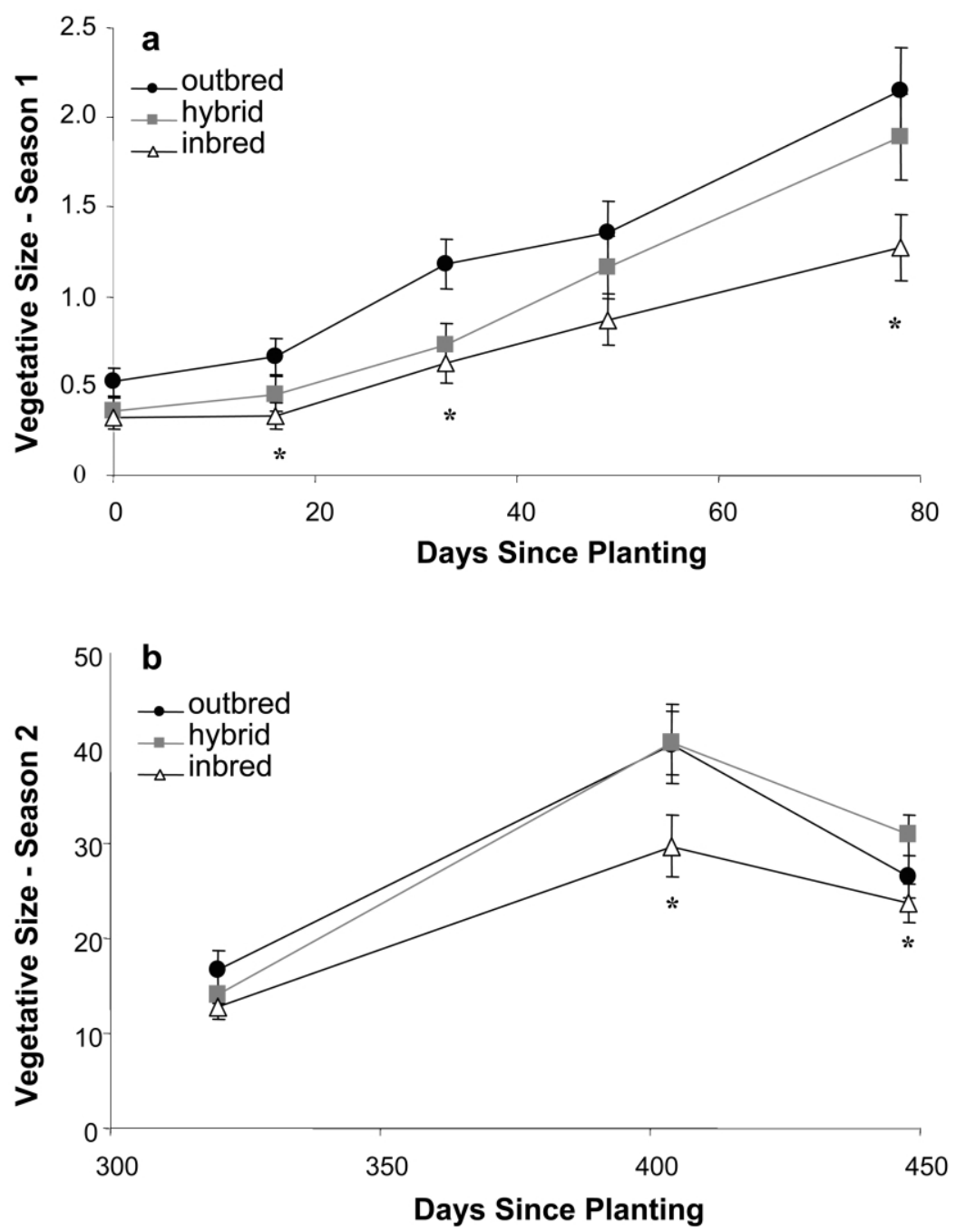

Figure 3: Means ( \pm 1 SE) vegetative size of outbred, hybrid, and inbred plants of Piriqueta caroliniana over the $(a)$ first and $(b)$ second growing seasons. Vegetative size was estimated as the product of plant height and leaf number. Asterisks indicate significant differences among cross groups.

higher performance (vegetative size, total reproductive output) of $F_{1}$ hybrids and outbred parentals is consistent with the hypothesis that release from inbreeding had heterotic effects on the vegetative size of first-generation hybrids. Overall mortality during the 2 years of this study was lower for $F_{1}$ hybrids than for inbred or outbred parentals, suggesting that heterosis may be even greater for crosses between more distantly related lineages. Dobzhansky-Muller incompatibilities due to cytonuclear interactions were evident from differences in the fitness of reciprocal hybrids in both the $F_{1}$ and backcross generations.

Heterotic effects in the hybrid offspring of a normally inbred parental taxon may have consequences for rates and patterns of introgression. Offspring from interpopu- lation crosses would have an intrinsic advantage over the inbred members of the local population in which they grew, which would facilitate the incorporation of foreign alleles into the gene pool (Richards 2000; Ebert et al. 2002). In the case of Piriqueta, crosses between populations produced offspring with higher rates of germination, vegetative growth, survival, and reproduction than offspring from within-population crosses. Because the contrast between outbred and inbred genotype performance was quite marked in most cases, interpopulation pollen dispersal must be extremely rare. Thus, inbreeding in small populations and restricted gene flow appears to have rendered some Piriqueta populations susceptible to the invasion and spread of novel genetic elements through hybridization. A crucial step in this process is the formation of early- 
Table 2: Mean $( \pm 1 \mathrm{SE})$ vegetative size at the end of the first and second season for inbred and outbred genotypes of Piriqueta caroliniana

\begin{tabular}{lccc}
\hline & Size, season 1 & Size, season 2 & Total reproduction \\
\hline $\mathrm{C}_{\mathrm{i}}$ & $.33 \pm .15$ & $20.91 \pm 3.60$ & $.24 \pm .14$ \\
$\mathrm{C}_{\mathrm{o}}$ & $1.77 \pm .48$ & $17.28 \pm 2.60$ & $.32 \pm .14$ \\
$\mathrm{C}_{\mathrm{i}}$ vs. $\mathrm{C}_{\mathrm{o}}(P)$ &. $\mathbf{0 0 6 9}$ & .35 & .77 \\
$\mathrm{H}_{\mathrm{i}}$ & $1.40 \pm .30$ & $23.83 \pm 3.55$ & $.27 \pm .10$ \\
$\mathrm{H}_{\mathrm{o}}$ & $2.07 \pm .30$ & $31.92 \pm 3.64$ & $.61 \pm .25$ \\
$\mathrm{H}_{\mathrm{i}}$ vs. $\mathrm{H}_{\mathrm{o}}(P)$ & .16 & .0164 & .34 \\
$\mathrm{~V}_{\mathrm{i}}$ & $2.36 \pm .43$ & $25.13 \pm 3.36$ & $.31 \pm .14$ \\
$\mathrm{~V}_{\mathrm{o}}$ & $2.83 \pm .51$ & $30.32 \pm 5.27$ & $.75 \pm .35$ \\
$\mathrm{~V}_{\text {i vs. }} \mathrm{V}_{\text {o }}(P)$ & .25 & .57 & .22 \\
\hline
\end{tabular}

Note: Mean vegetative size includes estimated aboveground biomass and plant height $\times$ leaf number, a dimensionless index. Subscript " $\mathrm{i}$ " $=$ inbred; subscript "o" = outbred. Results from contrast tests between pairs of inbred versus outbred parental genotypes are given, with significant probabilities in bold type.

generation hybrids in their host populations because fitness of these individuals determines the population's trajectory toward either incorporation of foreign genetic elements or maintenance of its original genetic composition.

Assessing the fitness of perennial organisms is complicated because lifetime reproductive success can be difficult to estimate. However, when comparing genotypes growing in a single environment, relative size at early life stages is often a good predictor of reproductive value (i.e., future survival and reproduction; Caswell 1989), which should be a fair surrogate for lifetime fitness. In the case of $P i$ riqueta, the amount of aboveground biomass accumulated during the first growing season appears to be a critical life stage because it was a strong predictor of overwinter survival and vegetative growth in the second season. Smaller plants had higher mortality, so cross types with smaller average sizes lost the most individuals. Culling of the smallest individuals from the population equalized the postwinter plant sizes among cross groups and types, and the magnitude of differences among groups and types decreased in the second season.

In this study, we used common gardens near the center of the naturally occurring hybrid zone, with environmental conditions more similar to those found in natural $\mathrm{C}$ parental populations (dry, sandy soil) than in $\mathrm{V}$ populations (wet, fine-textured soil with more organic matter). With this in mind, it is not surprising that the performance of $\mathrm{C}$ genotypes was typically superior to that of $\mathrm{V}$ genotypes in this experiment. While this may be viewed as a limitation of the study, it is important to note that for any analysis of hybrid breakdown, comparisons need to be made within environments that may favor one or the other of the parental genotypes. Our comparisons of hybrid performance with midparent values carry the implicit as- sumption that any environment-dependent epistasis has minimal effects on hybrid fitness. We cannot necessarily exclude the possibility that performance of some $\mathrm{F}_{1}$ genotypes relative to parental genotypes would be different in more mesic environments. Because genotype $x$ environment interactions are common in plant populations (Via and Lande 1985; Fenster and Galloway 2000; Campbell and Waser 2001), interpretations of these data need to be made with this assumption in mind.

\section{Hybrid Zone Dynamics}

Our comparisons of offspring from intra- and interpopulation crosses indicate that populations of Piriqueta are relatively inbred, so predictions of $F_{1}$ hybrid success in natural populations should be based on comparisons between hybrids and parental genotypes from intrapopulation crosses. Survival and reproduction of first-generation hybrids generally exceeded that of inbred parental plants over two growing seasons, and we expect that the greater vigor of these genotypes would favor their establishment and persistence in inbred populations. Because our data indicate that $\mathrm{F}_{1}$ hybrids often reproduce at higher rates than inbred parental genotypes, even infrequent establishment of hybrids would be expected to facilitate backcrossing and put populations on a trajectory toward parental genotype displacement. Heterosis in first-generation hybrids would result in a numeric advantage for latergeneration hybrids over parentals, which could help explain the absence of parental populations or genotypes over the full breadth of this hybrid zone.

While $F_{1}$ hybrids were generally more fit than their inbred parental genotypes, several pairs of reciprocal hybrid crosses differed in their overall growth and reproduction. In particular, $F_{1}$ crosses made with the more southern 
Table 3: Mean ( $\pm 1 \mathrm{SE}$ ) vegetative size at the end of the first and second season and total reproduction for reciprocal $F_{1}$ hybrids of Piriqueta caroliniana

\begin{tabular}{lccc}
\hline & Size, season 1 & Size, season 2 & Total reproduction \\
\hline $\mathrm{CV}$ & $2.43 \pm .73$ & $40.56 \pm 5.36$ & $1.56 \pm .54$ \\
$\mathrm{VC}$ & $2.02 \pm .65$ & $24.25 \pm 3.91$ & $.93 \pm .41$ \\
$\mathrm{CV}$ vs. VC $(P)$ & .99 & .0532 & .24 \\
$\mathrm{CH}$ & $2.15 \pm .52$ & $26.99 \pm 3.59$ & $.82 \pm .41$ \\
$\mathrm{HC}$ & $1.15 \pm .34$ & $41.94 \pm 7.59$ & $1.37 \pm .55$ \\
$\mathrm{CH}$ vs. HC $(P)$ & .25 & .0106 & .21 \\
$\mathrm{HV}$ & $2.87 \pm .67$ & $31.68 \pm 3.94$ & $.27 \pm .18$ \\
VH & $.28 \pm .28$ & $19.38 \pm 5.11$ & $.56 \pm .31$ \\
HV vs. VH $(P)$ & $\mathbf{. 0 0 2 6}$ & $\mathbf{. 0 4 0 1}$ & .69 \\
\hline
\end{tabular}

Note: Mean vegetative size includes estimated aboveground biomass and plant height $\times$ leaf number, a dimensionless index. Size was measured during two seasons. Results from contrast tests between pairs of crosses are given, with significant probabilities in bold type.

genotype as the maternal parent (e.g., $\mathrm{VH}, \mathrm{VC}$ ) have less end-of-season biomass accumulation than the reciprocal crosses to the north $(\mathrm{HV}, \mathrm{CV})$. This trend was repeated in the backcross hybrid generation (e.g., greater biomass accumulation for $[\mathrm{CV}] \mathrm{V}$ vs. [VC]V genotypes). Firstgeneration hybrid genotypes from southward crosses did not attain significantly larger size than the corresponding inbred maternal plants, while hybrids from northern crosses produced substantially larger progeny than their inbred counterparts. This observation is of particular interest because it might partly explain the pattern of hybrid zone expansion, which appears to be almost strictly toward the north (Martin and Cruzan 1999). Larger fitness values of northern $\mathrm{F}_{1}$ crosses are consistent with the observed pattern of asymmetrical introgression in this Piriqueta hybrid zone and highlight the potential importance of cytonuclear interactions for hybrid zone dynamics (Burke et al. 1998a, 1998b; Levin 2004).

Levels of inbreeding depression tended to differ among the three parental genotypes, affecting both the amount of heterosis experienced by outbred genotypes and the susceptibility of these populations to invasion by foreign alleles. The contrast between overwinter survival rates of inbred versus outbred genotypes was consistently less pronounced for $\mathrm{V}$ than for $\mathrm{C}$ populations. This observation suggests that the $\mathrm{V}$ morphotype has purged its genetic load, perhaps via historical population bottlenecks, a pattern consistent with the hypothesis that $\mathrm{V}$ from the Bahamas recently colonized southern Florida (Maskas and Cruzan 2000). The lack of strong differences in fitness of inbred and outbred genotypes in $\mathrm{V}$ populations would also reduce the intrinsic advantage of migrant genomes (Ingvarsson and Whitlock 2000; Ebert et al. 2002; Saccheri and Brakefield 2002) and may contribute to the lack of introgression from hybrid populations into southern Florida (V) pop- ulations. While several other studies have noted the effects of experimentally induced bottlenecks on the loss of deleterious recessive alleles from populations (Byers and Waller 1999; Crnokrak and Barrett 2002), observations of the effects of natural episodes of restricted population size on genetic load are less common (e.g., Visscher et al. 2001; Ramsey et al. 2003).

\section{Genetic Architecture of Hybrid Fitness}

Comparison of first-generation hybrids with outbred parentals provides an appraisal of the contributions of heterosis and epistasis to hybrid fitness. If frequencies of shared deleterious alleles among populations were similar within and between taxa, we would expect fitness values of $F_{1}$ hybrids and the average outbred midparent fitness to be similar. This prediction assumes that the heterosis seen in hybrids is due to release from inbreeding and reflects the cumulative effects of dominance and overdominance at loci fixed for deleterious alleles in inbred parental populations. Four of the six first-generation hybrid types displayed first-season vegetative growth rates similar to those of outbred parental genotypes (i.e., $\mathrm{CH}$, CV, VC, and HV). However, several hybrids had higher levels of reproduction than their outbred parentals (e.g., $\mathrm{CH}, \mathrm{HC}$, and $\mathrm{CV}$ ), which suggests that crosses to more distantly related populations may have produced more exaggerated heterotic effects.

Instances in which hybrids have higher fitness than outbred parentals could be due to a greater proportion of heterozygous loci in $F_{1}$ crosses. Assuming that many loci of small effect contribute to inbreeding depression (Charlesworth and Charlesworth 1987, 1999; Byers and Waller 1999; Crnokrak and Barrett 2002; Keller and Waller 2002), we might expect the proportion of loci fixed for 

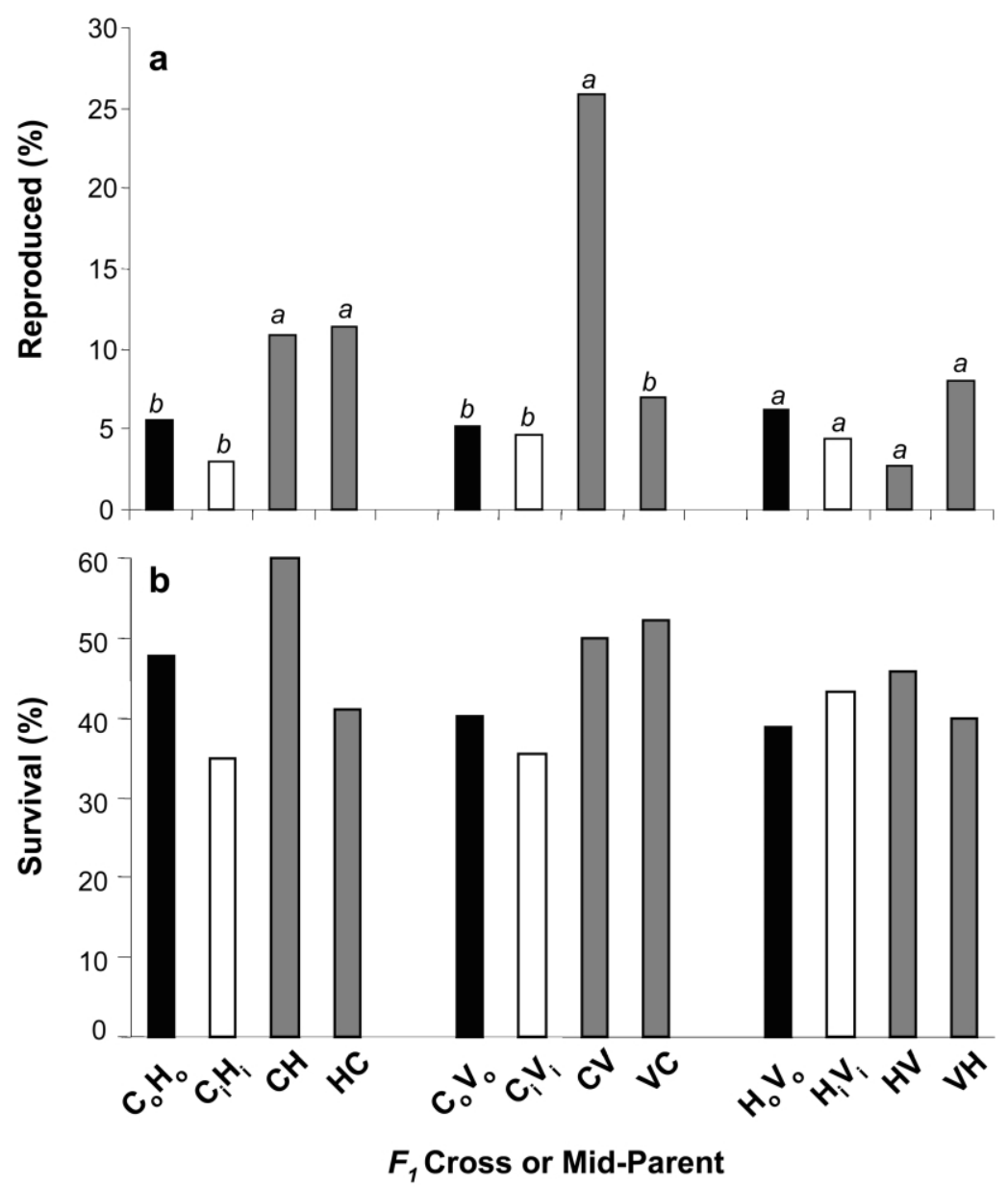

Figure 4: Means of outbred, inbred, and hybrid genotypes of Piriqueta caroliniana for (a) percent of plants that reproduced and $(b)$ percent survival to the end of the second growing season. Because data indicate frequencies, no standard errors are included. $F_{1}$ hybrid reciprocal crosses are grouped with the midparent values of both inbred (subscript "i") and outbred (subscript "o") parental lines. Within each family group (outbred midparent, inbred midparent, and reciprocal hybrids), means sharing a letter do not differ significantly. Survival to the end of the second growing season did not vary among cross types.

the same deleterious recessive alleles to be higher among genotypes from populations of the same taxon than populations from divergent lineages. Several lines of evidence support this interpretation. First, crosses between the most geographically distant populations $(\mathrm{C} \times \mathrm{V}$; Maskas and Cruzan 2000) displayed the highest degree of heterosis for reproduction relative to the outbred midparent average. Second, crosses between hybrid derivative populations and other parental morphotypes (i.e., $\mathrm{H} \times \mathrm{V}$ and $\mathrm{C} \times \mathrm{H}$ ) had moderate levels of heterosis compared with outbred parental crosses. In these cases, HV hybrids displayed the weakest heterotic effects, which is consistent with the observation that $\mathrm{V}$ populations have a low genetic load. For $\mathrm{CH}$ hybrids, on the other hand, the level of heterosis was intermediate, perhaps because populations of both paren- tal genotypes harbored higher levels of genetic load. It is also important to note that the $\mathrm{C}$ populations from central Florida, presumably responsible for the generation of $\mathrm{H}$ populations, were derived from a separate Pleistocene refuge than northern $\mathrm{C}$ populations (Maskas and Cruzan 2000). Hence, we expect that $\mathrm{C}$ and $\mathrm{H}$ populations would be less closely related and share fewer deleterious recessive alleles than $\mathrm{V}$ and $\mathrm{H}$ populations. The patterns of fitness observed for these hybrid crosses support the hypothesis that heterozygosity and its consequent masking of deleterious recessive alleles can produce heterotic effects for crosses between relatively divergent lineages.

Heterosis appeared to be prevalent in most of these $\mathrm{F}_{1}$ hybrid crosses, but in some cases there was evidence of epistasis, manifest as significant differences between hy- 


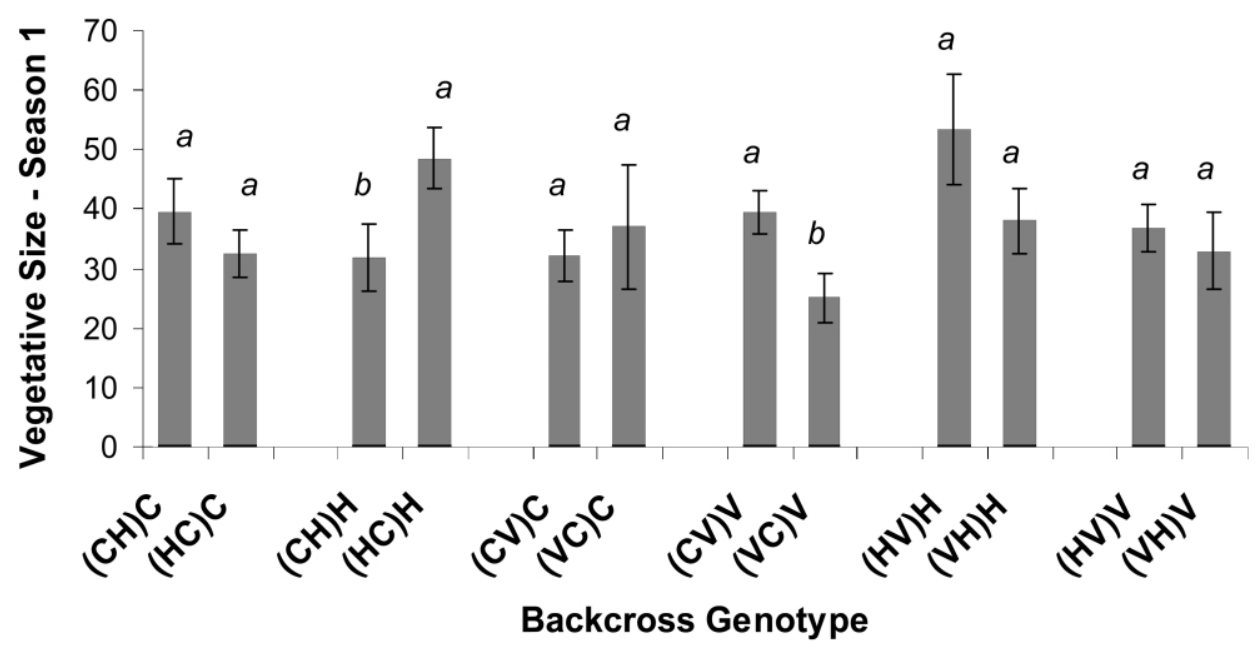

Figure 5: Means ( \pm 1 SE) of backcross genotypes of Piriqueta caroliniana for vegetative size at end of the first growing season. Vegetative size was estimated as the product of plant height and leaf number. Within each pair of reciprocal crosses, means sharing a letter do not differ significantly.

brids from reciprocal crosses. In particular, $\mathrm{HV}$ versus $\mathrm{VH}$ $\mathrm{F}_{1}$ crosses produced offspring with significantly different growth rates in the first season, and CV versus VC hybrids differed in second-season growth. One possible explanation for this difference is maternal effects (Roach and Wulff 1987), but this is unlikely because maternal effects on fitness are not consistent. For example, VH hybrids had one of the lowest fitness values, but hybrids from $\mathrm{V} \times \mathrm{C}$ crosses had relatively high (though lower than their reciprocal counterparts) fitness. A second possibility is that the observed lower fitness for particular nuclear-cytoplasmic combinations is due to hybrid dysgenesis, which has been observed in Drosophila (i.e., reduced hybrid fitness due to activity of transposable elements; Kidwell et al. 1977). This is probably not occurring in Piriqueta hybrids because we would expect quiescent transposable elements to become active in foreign cytoplasmic backgrounds. However, the most severe fitness losses in hybrids were for the $\mathrm{H}$ nuclear genome in association with both foreign (V) and native $(\mathrm{H})$ cytoplasmic genomes (i.e., $\mathrm{VH}$ and $\mathrm{HC} \mathrm{F}_{1}$ hybrid types for vegetative size in the first season), indicating that hybrid dysgenesis is not likely to be responsible for the observed patterns of fitness in these hybrids. Note also that these apparent cytonuclear effects on fitness are not likely to be due to the maternal environment because the same general pattern of second-season fitness for $\mathrm{CH}, \mathrm{CV}$, and $\mathrm{VH} \mathrm{F}_{1}$ reciprocal crosses was apparent for the reciprocal backcross hybrids. Although there may be other contributing factors, the data from these Piriqueta hybrid crosses are most consistent with the hypothesis that cytonuclear epistasis is responsible for the observed pat- terns of asymmetrical hybrid fitness losses for these reciprocal crosses.

Fitness reductions in first-generation hybrids have been documented in a wide variety of plants and animals (Dobzhansky 1937; Muller 1942; Clausen 1951, 1962; Mayr 1963; Barton and Gale 1993), but many of these experiments were not designed to test for cytonuclear interactions. Of the investigations that have examined the relationship between cytoplasmic background and hybrid fitness, most did not find cytoplasmic effects until the second hybrid generation (e.g., Breeuwer and Werren 1995; Burke et al. 1998b; Galloway and Fenster 1999; Willett and Burton 2001). In our experiments, however, cytonuclear effects were observed in both $\mathrm{F}_{1}$ and backcross hybrid generations. The potential for large effects of cytonuclear interactions on hybrid fitness in Piriqueta and other species (e.g., Ipomopsis; Campbell and Waser 2001) is perhaps not surprising given the large number of regulatory and transport interactions between nuclear and organelle genomes (Gillham 1997). As more analyses test for directional effects in hybrid crosses, more accurate estimates of the prevalence of cytonuclear epistasis in firstgeneration hybrids will become possible.

\section{Summary and Conclusions}

It is clear from these analyses that interpretations of $F_{1}$ performance depend largely upon the set of parental crosses to which hybrids are compared and may be strongly affected by the direction of the hybrid cross. In previous studies comparing parental and hybrid genotypes, 13 of 
24 cases reported that the fitness of $\mathrm{F}_{1}$ was equal or higher than parental fitness (table 1; Scribner 1993; Emms and Arnold 1997; Campbell et al. 1998, 2002; Hatfield and Schluter 1999; Semlitsch et al. 1999; Vamosi and Schluter 1999, 2002; Dunham and Argue 2000; Campbell and Waser 2001; Fritz et al. 2001; Parris 2001a, 2001b, 2001c; Parris et al. 2001; Promislow et al. 2001; Schwenk et al. 2001; Andersen et al. 2002; Pages et al. 2002; Schweitzer et al. 2002; Hauser et al. 2003). However, in almost all cases, the observed hybrid fitness advantage could have been the result of heterosis because hybrids were compared with inbred parental genotypes. The study comparing the fitness of $F_{1}$ hybrids to outbred genotypes did not find any evidence of higher fitness for the hybrids (Dunham and Argue 2000), but because they made no comparison to inbred parental genotypes, we cannot assess the contribution of heterosis to hybrid fitness. As illustrated here with the Piriqueta hybrid complex, comparison of inbred and outbred parental genotypes with first-generation hybrids that possess both cytoplasmic genotypes can provide insights into the genetic processes contributing hybrid fitness and into factors affecting introgression patterns. Inclusion of both inbred and outbred parental genotypes and reciprocal crosses in hybridization studies will encourage more careful assessments of the causes and consequences of observed levels of hybrid fitness (Arnold and Hodges 1995; Arnold 1997). Additional empirical theoretical analyses of multigeneration hybrid fitness (e.g., Johnston et al. 2001) will provide a more thorough understanding of the consequences of heterosis and epistasis for patterns of introgression and for the evolutionary potential of novel hybrid populations.

\section{Acknowledgments}

This article a was significantly improved through discussion and comments on previous versions by A. Ramakrishnan and several anonymous reviewers. Technical assistance in the field and lab was provided by $\mathrm{B}$. Benz, S. Handy, M. Heard, J. Martin, K. McBreen, K. McQuinn, R. Roberts, P. Sochacki, and especially A. Fortner. Thanks also to personnel and colleagues at the Archbold Biological Field Station, especially E. Menges, for valuable discussion and logistical assistance. This research received financial support from National Science Foundation grant DEB-0080437 to M.B.C.

\section{Literature Cited}

Andersen, D. H., O. Pertoldi, V. Scali, and V. Loeschcke. 2002. Intraspecific hybridization, developmental stability and fitness in Drosophila mercatorum. Evolutionary Ecology Research 4:603-621. Anderson, E. 1949. Introgressive hybridization. Wiley, New York.
Anderson, E., and G. L. Stebbins Jr. 1954. Hybridization as an evolutionary stimulus. Evolution 8:378-388.

Arnold, M. L. 1997. Natural hybridization and evolution. Oxford University Press, New York.

Arnold, M. L., and S. A. Hodges. 1995. Are natural hybrids fit or unfit relative to their parents? Trends in Ecology \& Evolution 10: 67-71.

Barton, N. H., and K. S. Gale. 1993. Genetic analysis of hybrid zones. Pages 13-45 in R. G. Harrison, ed. Hybrid zones and the evolutionary process. Oxford University Press, New York.

Breeuwer, J., and J. Werren. 1995. Hybrid breakdown between two haplodiploid species: the role of nuclear and cytoplasmic genes. Evolution 49:705-717.

Burke, J. M., and M. L. Arnold. 2001. Genetics and the fitness of hybrids. Annual Review of Genetics 35:31-52.

Burke, J. M., T. J. Voss, and M. L. Arnold. 1998a. Genetic interactions and natural selection in Louisiana iris hybrids. Evolution 52:13041310.

Burke, J. M., S. E. Carney, and M. L. Arnold. 1998b. Hybrid fitness in the Louisiana irises: analysis of parental and F-1 performance. Evolution 52:37-43.

Byers, D. L., and D. M. Waller. 1999. Do plant populations purge their genetic load? effects of population size and mating history on inbreeding depression. Annual Review of Ecology and Systematics 30:479-513.

Campbell, D. R., and N. M. Waser. 2001. Genotype-by-environment interaction and the fitness of plant hybrids in the wild. Evolution 55:669-676.

Campbell, D. R., N. M. Waser, and P. G. Wolf. 1998. Pollen transfer by natural hybrids and parental species in an Ipomopsis hybrid zone. Evolution 52:1602-1611.

Campbell, D. R., N. M. Waser, and G. T. Pederson. 2002. Predicting patterns of mating and potential hybridization from pollinator behavior. American Naturalist 159:438-450.

Caswell, H. 1989. Matrix population models. Sinauer, Sunderland, MA.

Charlesworth, B., and D. Charlesworth. 1999. The genetic basis of inbreeding depression. Genetical Research 74:329-340.

Charlesworth, D., and B. Charlesworth. 1987. Inbreeding depression and its evolutionary consequences. Annual Review of Ecology and Systematics 18:237-268.

Clausen, J. 1951. Stages in the evolution of plant species. Cornell University Press, Ithaca, NY.

1962. Stages in the evolution of plant species. Cornell University Press, Ithaca, NY.

Coyne, J. A., and H. A. Orr. 1998. The evolutionary genetics of speciation. Philosophical Transactions of the Royal Society of London B 353:287-305.

Crnokrak, P., and S. C. H. Barrett. 2002. Perspective: purging the genetic load: a review of the experimental evidence. Evolution 56: 2347-2358.

Darwin, C. 1876. The effects of cross and self fertilization in the vegetable kingdom. J. Murray, London.

Dobzhansky, T. 1936. Studies on hybrid sterility. II. Localization of sterility factors in Drosophila pseudoobscura hybrids. Genetics 21: 113-135.

- 1937. Genetics of the evolutionary process. Columbia University Press, New York.

Dowling, T. E., and C. L. Secor. 1997. The role of hybridization and 
introgression in the diversification of animals. Annual Review of Ecology and Systematics 28:593-619.

Dunham, R. A., and B. J. Argue. 2000. Reproduction among channel catfish, blue catfish, and their $F_{1}$ and $F_{2}$ hybrids. Transactions of the American Fisheries Society 129:222-231.

Ebert, D., C. Haag, M. Kirkpatrick, M. Riek, J. W. Hottinger, and V. I. Pajunen. 2002. A selective advantage to immigrant genes in a Daphnia metapopulation. Science 295:485-488.

Emms, S. K., and M. L. Arnold. 1997. The effect of habitat on parental and hybrid fitness: transplant experiments with Louisiana irises. Evolution 51:1112-1119.

Fenster, C. B., and L. F. Galloway. 2000. Population differentiation in an annual legume: genetic architecture. Evolution 54:1157-1172.

Fisher, R. A. 1965. The theory of inbreeding. Academic Press, New York.

Fishman, L., and J. Willis. 2001. Evidence for Dobshansky-Muller incompatibilities contributing to the sterility of hybrids between Mimulus guttatus and M. nasutus. Evolution 55:1932-1942.

Fritz, R. S., C. G. Hochwender, D. A. Lewkiewicz, S. Bothwell, and C. M. Orians. 2001. Seedling herbivory by slugs in a willow hybrid system: developmental changes in damage, chemical defense, and plant performance. Oecologia (Berlin) 129:87-97.

Galloway, L. F., and C. B. Fenster. 1999. The effect of nuclear and cytoplasmic genes on fitness and local adaptation in an annual legume, Chamaecrista fasciculata. Evolution 53:1734-1743.

Gillham, N. 1997. Organelle genes and genomes. Oxford University Press, New York.

Grant, V. 1963. The origin of adaptations. Columbia University Press, New York.

_ 1981. Plant speciation. Columbia University Press, New York.

Haag, C. R., J. W. Hottinger, M. Riek, and D. Ebert. 2002. Strong inbreeding depression in a Daphnia metapopulation. Evolution 56:518-526.

Handy, S. M., K. McBreen, and M. B. Cruzan. 2004. Patterns of fitness and fluctuating asymmetry across a broad hybrid zone. International Journal of Plant Sciences 165:973-981.

Harrison, R. G. 1990. Hybrid zones: windows on evolutionary process. Oxford Survey of Evolutionary Biology 7:69-128.

Hartl, D. L., and A. G. Clark. 1997. Principles of population genetics. Sinauer, Sunderland, MA.

Hatfield, T., and D. Schluter. 1999. Ecological speciation in sticklebacks: environment-dependent hybrid fitness. Evolution 53:866873.

Hauser, T. P., C. Damgaard, and R. B. Jorgensen. 2003. Frequencydependent fitness of hybrids between oilseed rape (Brassica napus) and weedy B. rapa (Brassicaceae). American Journal of Botany 90: 571-578.

Hedgecock, D., D. J. McGoldrick, and B. L. Bayne. 1995. Hybrid vigor in Pacific oysters: an experimental approach using crosses among inbred lines. Aquaculture 137:285-298.

Hedrick, P. W., and P. S. Miller. 1992. Conservation genetics: techniques and fundamentals. Ecological Applications 2:30-46.

Ingvarsson, P. K., and M. C. Whitlock. 2000. Heterosis increases the effective migration rate. Proceedings of the Royal Society of London B 267:1321-1326.

Johnston, J., D. Grise, L. Donovan, and M. L. Arnold. 2001. Environment-dependent performance and fitness of Iris brevicaulis, I. fulva (Iridaceae), and hybrids. American Journal of Botany 88:933-938.
Keller, L. F., and D. M. Waller. 2002. Inbreeding effects in wild populations. Trends in Ecology \& Evolution 17:230-241.

Kidwell, M. G., J. F. Kidwell, and J. A. Sved. 1977. Hybrid dysgensis in Drosophila melanogaster: a syndrome of aberrant traits including mutation, sterility, and male recombination. Genetics 86:813-833.

Knobloch, I. W. 1972. Intergeneric hybridization in flowering plants. Taxon 21:97-103.

Levin, D. A. 2004. Nucleocytoplasmic incompatibility fosters speciation. Pages 30-37 in J. W. Q. Cronk, R. H. Ree, and I. E. P. Taylor, eds. Plant adaptation: molecular genetics and ecology. NRC Research, Ottawa.

Lynch, M. 1991. The genetic interpretation of inbreeding depression and outbreeding depression. Evolution 45:622-629.

Marr, A. B., L. F. Keller, and P. Arcese. 2002. Heterosis and outbreeding depression in descendants of natural immigrants to an inbred population of song sparrows (Melospiza melodia). Evolution 56:131-142.

Martin, L. J., and M. B. Cruzan. 1999. Patterns of hybridization in the Piriqueta caroliniana complex in central Florida: evidence for an expanding hybrid zone. Evolution 53:1037-1049.

Maskas, S. D., and M. B. Cruzan. 2000. Patterns of intraspecific diversification in the Piriqueta caroliniana complex in eastern North America and the Bahamas. Evolution 54:815-827.

Mayr, E. 1963. Animal species and evolution. Harvard University Press, Cambridge, MA.

Muller, H. J. 1940. Bearing of the Drosophilla work on systematics. Pages 185-268 in J. Huxley, ed. The new systematics. Clarendon, Oxford.

- 1942. Isolating mechanisms, evolution and temperature. Biological Symposium 6:71-125.

Ornduff, R., and J. Perry. 1964. Reproductive biology of Piriqueta caroliniana (Turneraceae). Rhodora 66:100-109.

Orr, H. A. 1995. The population genetics of speciation: the evolution of hybrid incompatibilities. Genetics 139:1803-1813.

- 1996. Dobzhansky, Bateson, and the genetics of speciation. Genetics 144:1331-1335.

Orr, H. A., and M. Turelli. 2001. The evolution of postzygotic isolation: accumulating Dobzhansky-Muller incompatibilities. Evolution 55:1085-1094.

Pages, J. R., V. R. Southgate, L. A. T. Tchuente, and J. Jourdane. 2002. Experimental evidence of hybrid breakdown between the two geographical strains of Schistosoma intercalatum. Parasitology 124:169-175.

Parris, M. J. 2001a. High larval performance of leopard frog hybrids: effects of environment-dependent selection. Ecology 82:30013009.

- 2001b. Hybridization in leopard frogs (Rana pipiens complex): terrestrial performance of newly metamorphosed hybrid and parental genotypes in field enclosures. Canadian Journal of Zoology 79:1552-1558.

- 2001c. Hybridization in leopard frogs (Rana pipiens complex): variation in interspecific hybrid larval fitness components along a natural contact zone. Evolutionary Ecology Research 3: 91-105.

Parris, M. J., C. W. Laird, and R. D. Semlitsch. 2001. Differential predation on experimental populations of parental and hybrid leopard frog (Rana blairi and Rana sphenocephala) larvae. Journal of Herpetology 35:479-485.

Promislow, D. E. L., C. F. Jung, and M. L. Arnold. 2001. Age-specific 
fitness components in hybrid females of Drosophila pseudoobscura and D. persimilis. Journal of Heredity 92:30-37.

Ramsey, M., L. Seed, and G. Vaughton. 2003. Delayed selfing and low levels of inbreeding depression in Hibiscus trionum (Malvaceae). Australian Journal of Botany 51:275-281.

Richards, C. M. 2000. Inbreeding depression and genetic rescue in a plant metapopulation. American Naturalist 155:383-394.

Rieseberg, L. H., M. A. Archer, and R. K. Wayne. 1999. Transgressive segregation, adaptation and speciation. Heredity 83:363-372.

Roach, D. A., and R. D. Wulff. 1987. Maternal effects in plants. Annual Review of Ecology and Systematics 18:209-235.

Saccheri, I. J., and P. M. Brakefield. 2002. Rapid spread of immigrant genomes into inbred populations. Proceedings of the Royal Society of London B 269:1073-1078.

SAS Institute. 1999. SAS statistical analysis software. SAS Institute, Cary, NC.

Schemske, D. 2000. Understanding the origin of species. Evolution 54:1069-1073.

Schluter, D. 1998. Ecological causes of speciation. Pages 114-129 in S. Berlocher, ed. Endless forms: species and speciation. Oxford University Press, New York.

Schweitzer, J. A., G. D. Martinsen, and T. G. Whitham. 2002. Cottonwood hybrids gain fitness traits of both parents: a mechanism for their long-term persistence? American Journal of Botany 89: 981-990.

Schwenk, K., M. Bijl, and S. B. J. Menken. 2001. Experimental interspecific hybridization in Daphnia. Hydrobiologia 442:67-73.

Scribner, K. T. 1993. Hybrid zone dynamics are influenced by genotypic-specific variation in life history traits: experimental evidence from hybridizing Gambusia species. Evolution 47:632-646.

Semlitsch, R. D., J. Pickle, M. J. Parris, and R. D. Sage. 1999. Jumping performance and short-term repeatability of newly metamorphosed hybrid and parental leopard frogs (Rana sphenocephala and Rana blairi). Canadian Journal of Zoology 77:748-754.

Stebbins, G. L. 1950. Variation and evolution in plants. Columbia University Press, New York.
1959. The role of hybridization in evolution. Proceedings of the American Philosophical Society 103:231-251.

Templeton, A. R. 1981. Mechanisms of speciation: a population genetic approach. Annual Review of Ecology and Systematics 12:2348.

Turelli, M., and H. A. Orr. 2000. Dominance, epistasis and the genetics of postzygotic isolation. Genetics 154:1663-1679.

Vamosi, S. M., and D. Schluter. 1999. Sexual selection against hybrids between sympatric stickleback species: evidence from a field experiment. Evolution 53:874-879.

. 2002. Impacts of trout predation on fitness of sympatric sticklebacks and their hybrids. Proceedings of the Royal Society of London B 269:923-930.

Via, S. 2002. The ecological genetics of speciation. American Naturalist 159(suppl.):S1-S7.

Via, S., and R. Lande. 1985. Genotype-environment interaction and the evolution of phenotypic plasticity. Evolution 39:505-522.

Visscher, P. M., D. Smith, S. J. G. Hall, and J. A. Williams. 2001. A viable herd of genetically uniform cattle: deleterious alleles seem to have been purged in a feral strain of inbred cows. Nature 409: 303.

Wang, J., and M. B. Cruzan. 1998. Interspecific mating in the Piriqueta caroliniana (Turneraceae) complex: effects of pollen load size and composition. American Journal of Botany 85:1172-1179.

Weir, B. S., and C. C. Cockerham. 1984. Estimating F-statistics for the analysis of population structure. Evolution 38:1358-1370.

Willett, C. S., and R. S. Burton. 2001. Viability of cytochrome C genotypes depends on cytoplasmic backgrounds in Tigriopus californicus. Evolution 55:1592-1599.

Wright, S. 1932. The roles of mutation, inbreeding, crossbreeding and selection in evolution. Proceedings of the Sixth International Congress of Genetics 1:356-366.

Zar, J. H. 1999. Biostatistical analysis. Prentice Hall, Upper Saddle River, NJ.

Editor: Michael C. Whitlock 
Copyright of American Naturalist is the property of University of Chicago Press and its content may not be copied or emailed to multiple sites or posted to a listserv without the copyright holder's express written permission. However, users may print, download, or email articles for individual use. 